\title{
Competitiveness Factors for China's Online Game Industry Based on Diamond Model
}

\author{
Hu Ni, Jin Yazhi \\ Institute of Economics, Shanghai University, Shanghai, China
}

\section{Email address:}

910224888@qq.com (Hu Ni)

\section{To cite this article:}

$\mathrm{Hu} \mathrm{Ni}$, Jin Yazhi. Competitiveness Factors For China's Online Game Industry Based on Diamond Model. Science Journal of Business and Management. Vol. 3, No. 6, 2016, pp. 293-301. doi: 10.11648/j.sjbm.20150306.21

\begin{abstract}
At present, the online game has become one of the cultural and creative industries which is in the most rapidly growing, the huge market potential and the most far-reaching Internet industry.This paper, using the modified Porter's Diamond Model, in seven aspects to analyze the influencing factors of online game industry's competitiveness and they are the production elements, demand conditions, support industry and related industries, enterprise strategy and competition, the government, chances and the absorption and innovation of knowledge. There is a lack of innovativeness in china's online game industry. The market is facing an oligopoly monopoly development problem and the financing system is not perfect became the restrictions on the developing of the online game industry in china.On the basis of above, the corresponding countermeasures and suggestions are put forward.
\end{abstract}

Keywords: The Online Game Industry, Industrial Competitiveness, Diamond Model, Factor Analysis

\section{基于钻石模型的中国网络游戏产业竞争力影响因素研究}

\section{胡妮, 靳雅芝}

经济学院, 上海大学, 上海市, 中国

\section{邮箱}

910224888@qq. com(胡妮)

\begin{abstract}
摘要：目前，网络游戏已成为文化创意产业中增长最迅速、市场潜力巨大、影响最深远的互联网产业。本文利用改造 后的波特经典的钻石模型，从生产要素、需求条件、支持产业与相关产业、企业战略结构与竞争、政府、机遇和知识 的吸收与创新七个方面来分析影响网络游戏产业竞争力的因素, 中国网络游戏产业创新性不足、市场朝着寡头型垄断 发展、融资体系不完善等成为了限制网络游戏产业发展的颈瓶。最后在此基础上提出相应的合理化对策和建议。
\end{abstract}

关键词：网络游戏产业，产业竞争力，钻石模型，因子分析

\section{1. 引言}

\section{1. 研究背景}

网络游戏经过十年来的快速发展，从无到有，已经从 一个游戏产业的分支发展成为目前国内游戏产业的支柱， 已成为融合高新技术的文化创意产业之一, 拥有着庞大的
受众基础和广泛的产业链条, 是全球网络经济中的重要组 成部分。中国网络游戏产业在中国互联网产业中, 拥有市 场潜力巨大、增长最快、影响最深远的特点, 发展潜力也 是巨大无比的。当前, 网络游戏行业已取得了瞩目的成就, 从2006年开始, 中国网络游戏市场规模就保持了 $50 \%$ 以上 的增长速度, 直至2009年才稍有所减缓, 发展速度和规模 都令人瞩目, 2014年网络游戏市场规模已达到 1108.1 亿元。 
[1]随着移动 $4 \mathrm{G}$ 和联通 $3 \mathrm{G}$ 等运营商的移动互联网的广泛推 出, 移动游戏迅速崛起, 给网络游戏行业带来了更多的发 展契机。

\section{2. 研究意义}

从理论意义上来看, 由于网络游戏产业是随着互联网 出现的新兴产业, 发展较晚, 中国内外关于产业这一大层 面的相关研究相对较少。目前的游戏产业相关研究文献大 都集中商业模式、产业发展、消费者行为、企业行为、法 律问题等方面, 从经济学的角度系统阐述游戏产业竞争力 影响因素相关的文献相对较少, 本文力求在这方面有所突 破。为了更贴合中国网络游戏行业的需要, 本文试图利用 改造后的波特经典的钻石模型, 分析影响网络游戏产业竞 争力的因素, 并在此基础上提出合理化对策和建议。

从现实意义上来看, 虽然目前中国网络游戏产业仍处 于高增长阶段, 但依旧存在着很多问题, 比如行业的恶意 竞争, 游戏抄袭现象严重, 商业发展模式落后等现象。若 在兴盛之时不注意营造健康可持续发展的市场氛围, 一旦 决堤, 或出现大幅度波动, 那这一切弊病都将彻底显现。 本文旨在分析网络游戏产业存在的问题上并提出意见和 建议, 为网络游戏的健康发展打下基础。

\section{2. 相关理论介绍}

波特钻石理论模型（Michael Porter diamond Mode1） 又称钻石理论、菱形理论及国家竞争优势理论。该模型旨 在探讨一国产业或企业的竞争优势来源问题。它强调不仅 一国的所有行业和产品参与国际竞争, 并且要形成国家整 体的竞争优势, 而国家竞争优势的取得, 关键在于以下四 个基本要素和两个辅助要素的整合作用。生产要素、企业 战略、需求条件和相关产业等决定产业的竞争力, 这四个 要素之间是相互独立和相互影响, 与两个外生变量: 政府 和机遇组成一个完整的体系。[2]

本文根据中国网络游戏所处的发展环境和中国的经 济状况, 提出了改造后的钻石模型, 加入了一个核心, 即

“知识的吸收和创新” 以便研究成果能够更符合中国网络 游戏行业特征, 如图1所示。“钻石模型” 加了一个核心, 有了这个核心才能真正发展出自己产业的持续的竞争力。 现在与未来中国产业发展首先要培养自己的知识吸收与 创新能力, 其次在更大程度上参与国际产业分工体系, 并 在产业链中谋求好的位置, 进而在全球经济中保持与发展 自己的产业竞争力。 [3]

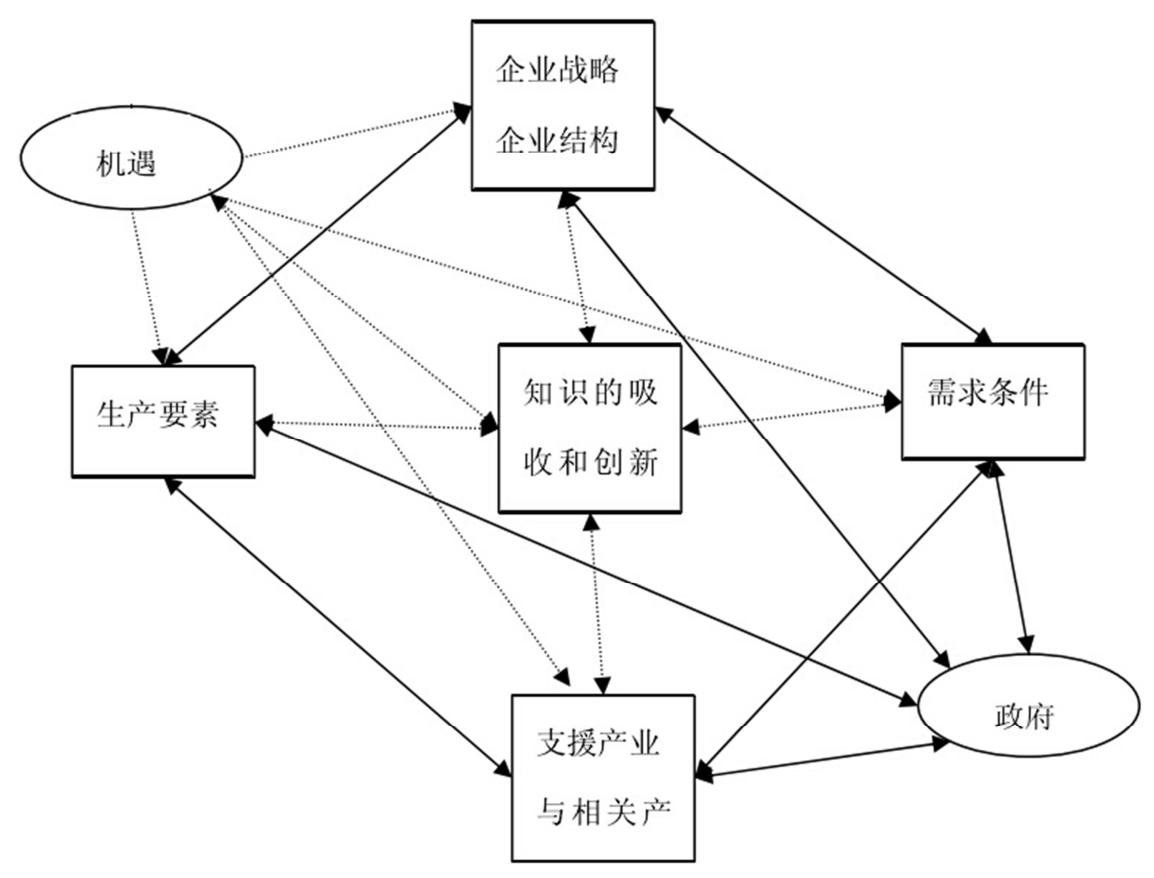

图1 改造后的钻石模型。

本文考虑到网络游戏行业是以高新技术为核心的文 化产业, 是创意产业经济结构中一个重要的组成部分, 因 此加入了此元素。一方面, 必须要把 “创意” 作为其发展 的首要因素，将产业发展的核心理念定位于 “创意”。一 款成功的网络游戏必须在制作、生产、营销等诸多环节中 融入创意的元素，结合现有的高科技技术，以创意理念去 带动游戏的发展。如果没有独特的 “创意”, 网络游戏便 失去了存在的灵魂, 在竞争激烈的市场当中就很难获得成 功。另一方面, 企业要向美日韩等游戏发达国家学习, 通
过优秀游戏作品的借鉴和知识的吸收, 得到灵感和启发, 进而更好的为自主研发游戏之路打下牢固的基础。

\section{3. 中国网络游戏产业竞争力影响因素分析}

\section{1. 生产要素分析}

\subsection{1. 人力资源对网络游戏产业竞争力的影响分析}

网络游戏产业属于文化产业的一种, 需要创新性和 技术性两者兼备, 二者缺一不可。因此网络游戏行业更 
需要的创新性人才, 比如网络游戏软件设计师, 计算机 高级程序员, 游戏软件美术设计和3D动画设计。但是在 这个拥有巨大潜力的新兴朝阳网络游戏行业中, 却面临 着人才缺乏的局面。导致这种现象发生的原因之一是, 高校对游戏的职业培训屈指可数, 对于想毕业后进入游 戏行业的学生, 只能通过参加专业的游戏培训机构来增 加入职游戏行业的机会; 而在韩国, 却有专为游戏设立 的游戏大学, 大学里开设剧情创作学科、游戏策划学科、 游戏程序学科、游戏美工学科、游戏机械工学科等游戏
相关学科。这种专业化的培养, 给韩国游戏行业带来了 很多发展的契机。[4]

目前中国网游研发的从业人数正在逐年上涨的趋势, 其中 2007 年上涨较快, 原因是当时网络游戏正处于中国刚 兴起阶段, 吸引了大批企业纷纷投资网络游戏产业（如图 2所示）。而相比网络游戏发达的韩国，2014年游戏行业 总体从业人数为 8 万 7281 人, 其中游戏研发发行行业从业 人员达 3 万 9221 人, 占总人数的 $44.9 \%$, 游戏流通消费行业 从业人数为 4 万 8060 万人, 占总人数的 $55.1 \%$, 由此可见, 中国研发力量比韩国薄弱很多。

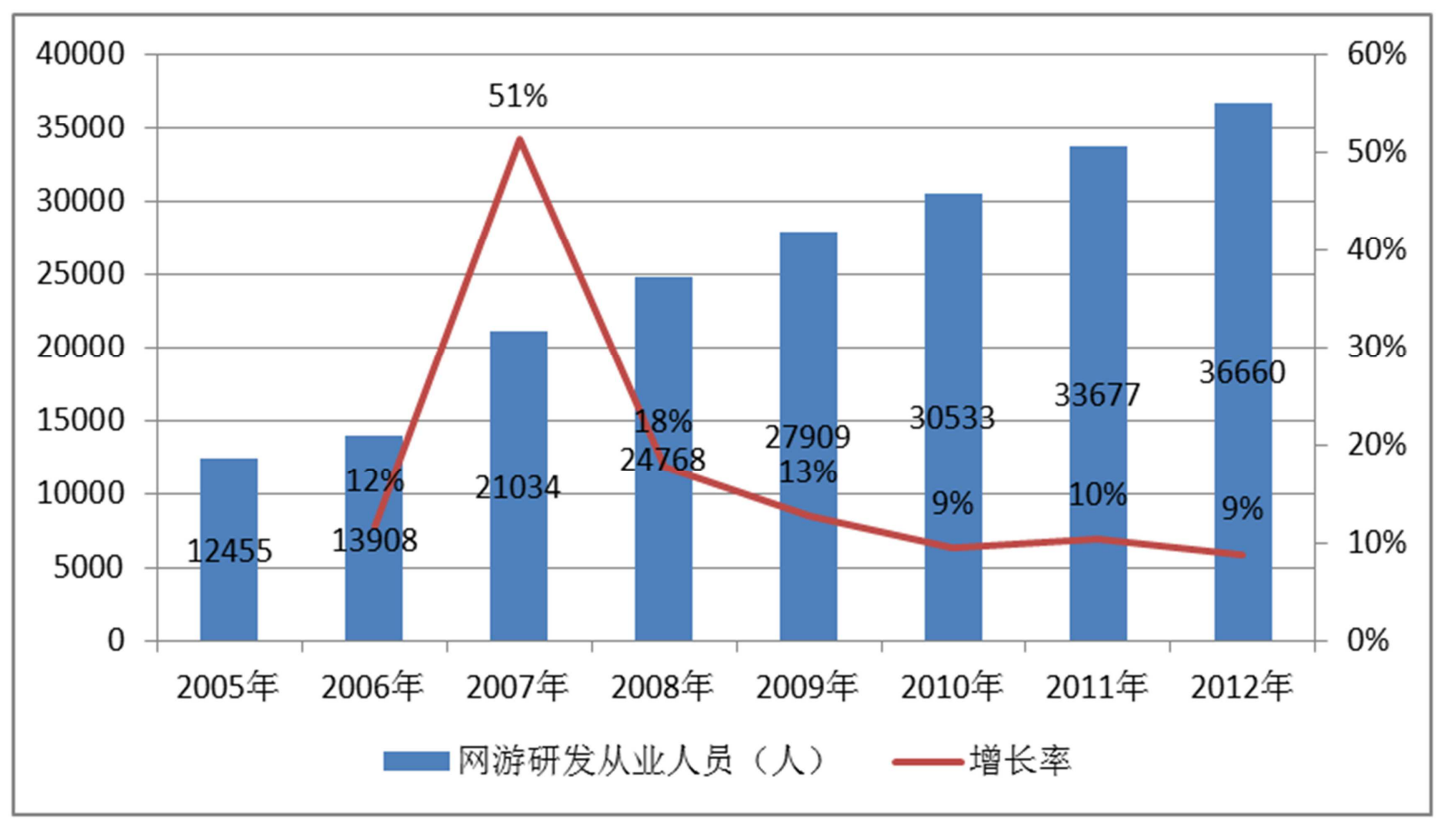

(数据来源: 艾瑞咨询)

图2 2004-2012年网游研发从业人员（人）。

\section{1. 2. 资本对网络游戏产业竞争力的影响分析}

对于一款精品网络客户端游戏的研发到运营, 不仅仅 需要漫长的周期, 更需要大量的资金投入。《魔兽世界》 作为至今全球最受欢迎的网络游戏无疑是成功的, 数据显 示，该款游戏从 2000 年底开始研发，用了近 5 年时间，投 资约 4000 万美元，折合人民币约 2.7 亿。但这只是游戏公 测的时候的研发费用, 而后续资料片的更新, 还需要增加 好几倍。因此, 对于客户端类游戏属于高风险类。在中国 只有大型企业如腾讯、网易等才会自主研发客户端类游戏。 而对于中小企业来说, 手机游戏是他们的最佳选择。由于 手游的赚钱策略就是 “薄利多销” , 自然不会投入过多的 研发成本。一般情况下，一款手机游戏的研发时间半年到 一年, 所需人员二十人, 不管是物力还是人力, 开发成本 比客户端类游戏要少得多。游戏开放商对于手机游戏采用 快速上线, 快速迭代的策略, 快速做出第一个版本, 展示 核心玩法, 上线之后再根据玩家反馈来调整、修改、更新 游戏。如果游戏没有盈利的可能则可以放弃开始下一个项 目, 若初期表现还不错或者能看到一定的潜力, 则可以根 据初期的数据和玩家的反馈更有针对性的调整和更新, 通
过这种将游戏从产品转换到服务的思路, 成本和风险都可 以大大降低。

\section{2. 需求条件分析}

在迈克尔波特的钻石模型中, 国内需求市场是产业发 展的动力。国内市场与国际市场的不同之处在于企业可以 及时发现国内市场的客户需求, 这是国外竞争对手所不及 的, 因此波特认为全球性的竞争并没有减少国内市场的重 要性, 而产业的长期发展离不开持续增长的市场需求。

近些年来, 随着互联网的高速发展, 网络游戏行业也 进入了快速发展时期。而究其原因, 则是来源于中国市场 的巨大需求。截至2014年6月, 中国网民规模达6.32亿, 半年共计新增网民 1442 万人, 从2010年起，网民数一直保 持 $30 \%$ 以上的增长速度并且逐年上升。互联网普及率为 46. 9\%，较2013年底提升了 1.1 个百分点（图3）。2014年6 月数据显示中国手机网民规模达 5.27 亿, 较 2013 年底增加 2699 万人，并从 2010 年手机用户规模数量一直保持 $65 \%$ 的 增长速度, 网民中使用手机上网的人群占比进一步提升, 由 2013年的81.0\%提升至85.8\%（图4）。手机网民规模首 次超越传统电脑端网民规模, 而手机游戏的快速发展将是 网络游戏行业增长的新的引爆点。 [5] 


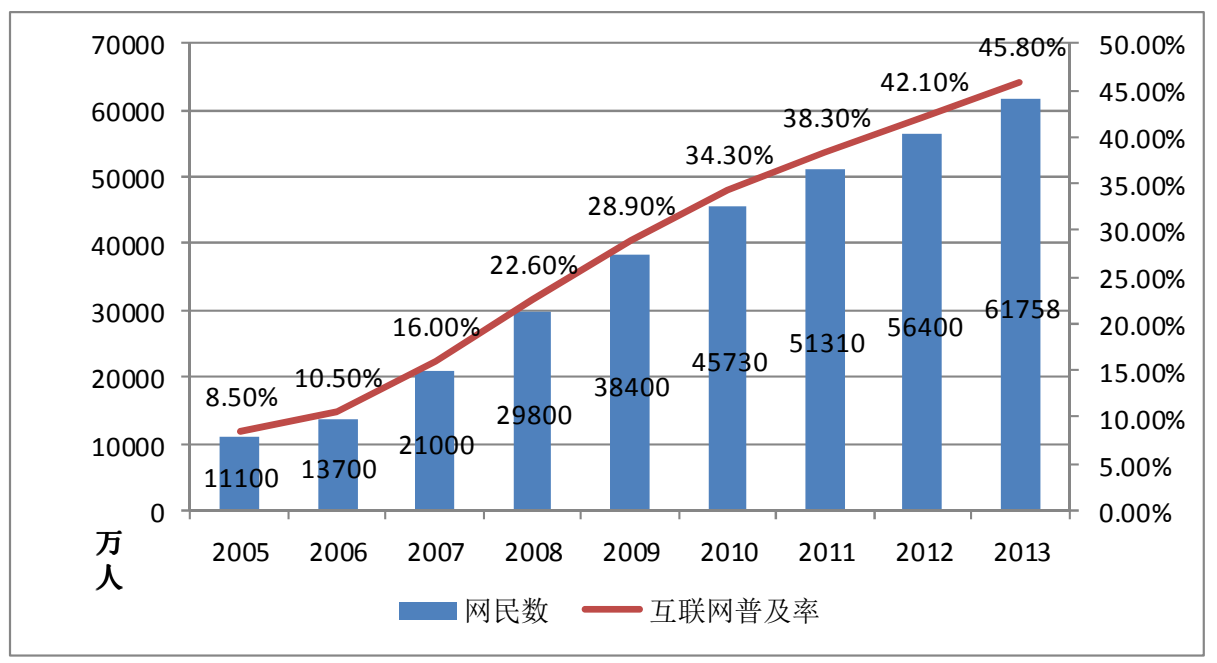

(数据来源: CNNIC：2014年第34次中国互联网络发展状况统计报告）

图3 中国网民规模与互联网普及率。

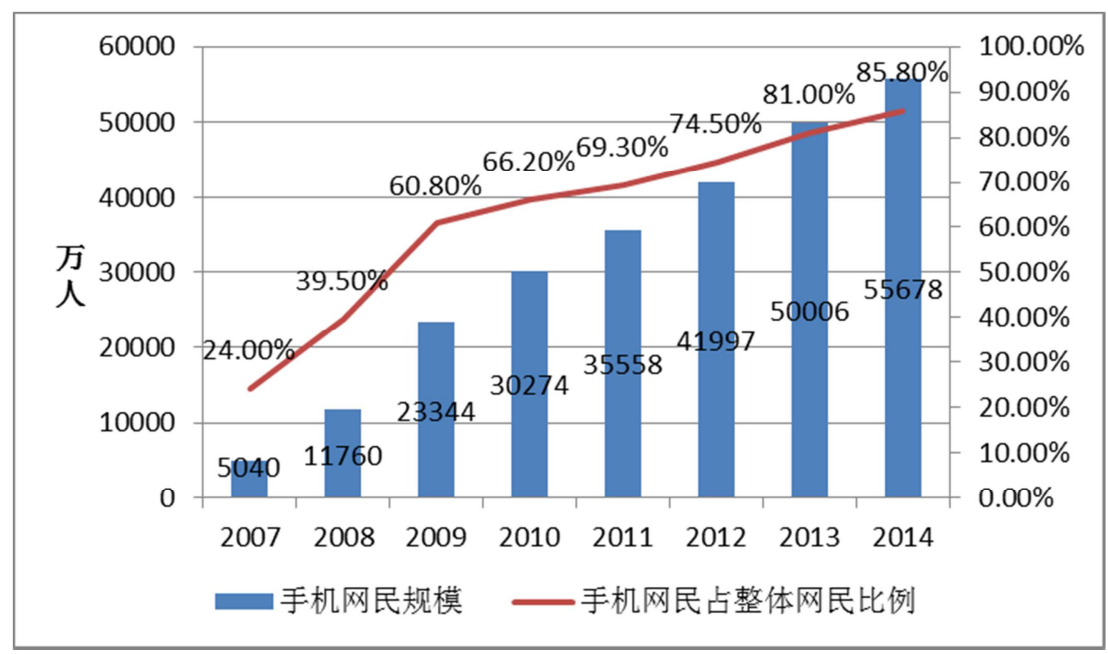

(数据来源：CNNIC：2014年第34次中国互联网络发展状况统计报告）

图4 中国手机网民规模及其占网民比例。

波特指出, 本地客户的本质非常重要, 特别是内行而 挑剔的客户。假如本地客户对产品、服务的要求或挑剔程 度在国际间数一数二, 就会激发出该国企业的竞争优势, 这个道理很简单, 如果能满足最难缠的顾客, 其它的客户 要求就不在话下。如图5所示, 网络游戏年龄超过 3 年的用 户占据全部网络游戏玩家的 $82 \%$ 左右。而网络游戏行业的付 费用户规模的增加其中很重要的一个原因是网络游戏走精 品路线, 提升了用户的粘性和产品认可度。因此, 用户的 持续贡献收入和用户规模的增加是网络游戏产业生存之道。 如图6所示, 自2008年以来, 中国游戏用户规模从 0.67 亿增加到 5.17 亿, 足足翻了近8倍, 从 2010年开始至 2013 年底, 中国网络游戏用户规模增长减缓, 使用率逐年下跌。 而2014年6月, 网民网络游戏的使用率出现了转折, 从2013 年底的 $54.7 \%$ 回升至 $58.2 \%$, 这主要归功于手机网络游戏用 户规模和使用率的大幅提升, 这是实现网络游戏整体逆转 的重要推动力。

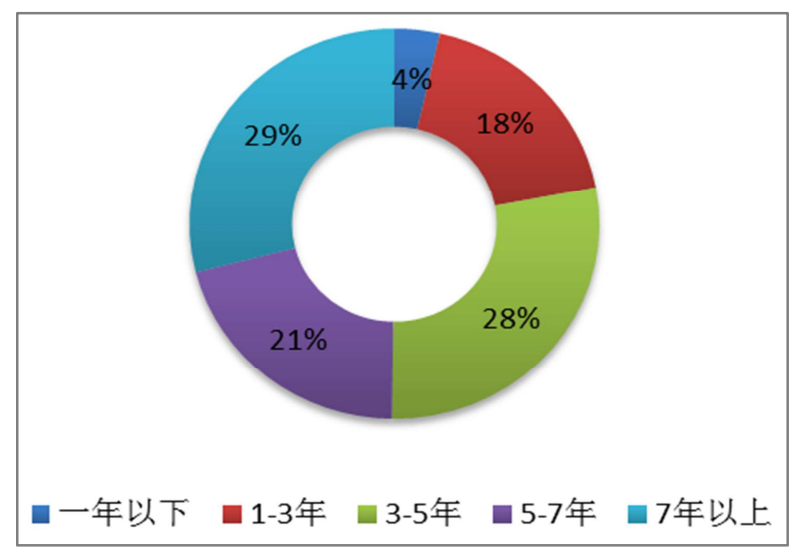

（数据来源：易观智库）

图5 2013年网络游戏用户游戏年龄构成。 


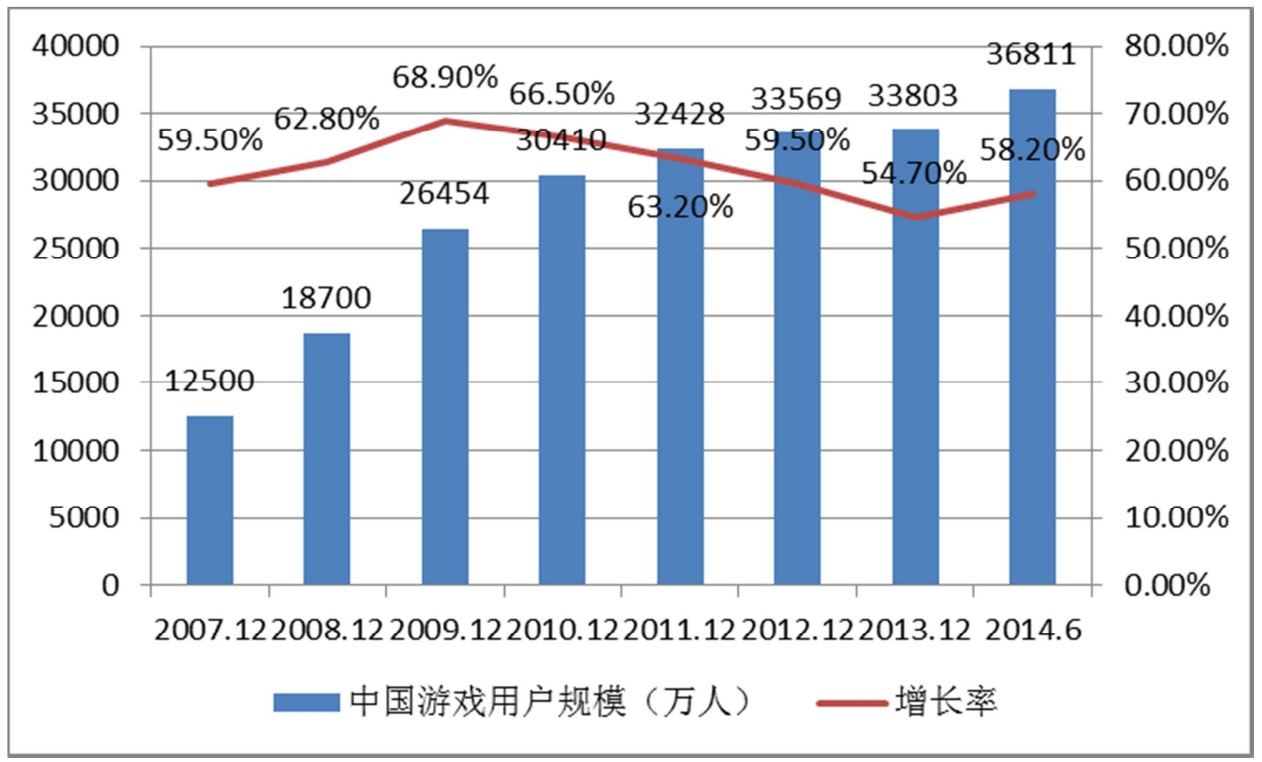

(数据来源: 中国互联网络发展状况统计调查)

图6 2007-2014中国游戏市场用户数量。

\section{3. 支持产业与相关产业分析}

\section{3. 1. 信息产业对网络游戏产业竞争力的影响分析}

从相关支持性产业来看, 网络游戏产业关系密切的行 业有计算机行业与互联网行业, 而目前作为异军突起的移 动通讯产业也对网络游戏有着重要影响。2014年, 移动电 话用户净增 5698 万户, 总数达 12.86 亿户, 移动电话用户 普及率达 94.5 部/百人，比上年提高 3.7 部/百人。据图 7 可知, 1949年以来, 中国的通讯水平正在逐步提高, 从1995 年移动电话普及率的 1.1 部/百人到 2014 年移动电话普 及率的 94.5 部/百人, 提高近 100 倍, 建国以来, 中国的通 讯行业飞跃式的发展, 这大大提升了智能手机的覆盖率。 近年来, 以 $4 \mathrm{G}$ 网络牌照的颁发和相关技术的普及为标志, 中国信息网络基础设施加速建设, 通信技术创新推动了互
联网和网络游戏产业的深度融合。智能手机的升级换代, 迎来新的一轮价格下调, 为网络游戏用户提供了更优质的 体验环境, 而移动宽带速度的提升, 运营商为抢占商机主 动下调资费价格, 更是给网络游戏发展创造了更有利的条 件, 引发了移动游戏的新增长爆点。

从图8中可以看出, 中国的互联网普及率仍处于较低 的水平为 $46.9 \%$, 超过了全球的平均水平 $40 \%$, 但是与美日 韩等互联网发达国家有较大的差距, 这也意味着中国与 IT 相关的产业有较大的增长空间。宽带互联网作为网游产业 的硬件基础, 宽带网速的大幅度提升以及覆盖率的全面普 及有利于网络用户的增长, 这对于网络游戏企业而言, 这 里蕴含着巨大的市场空间。

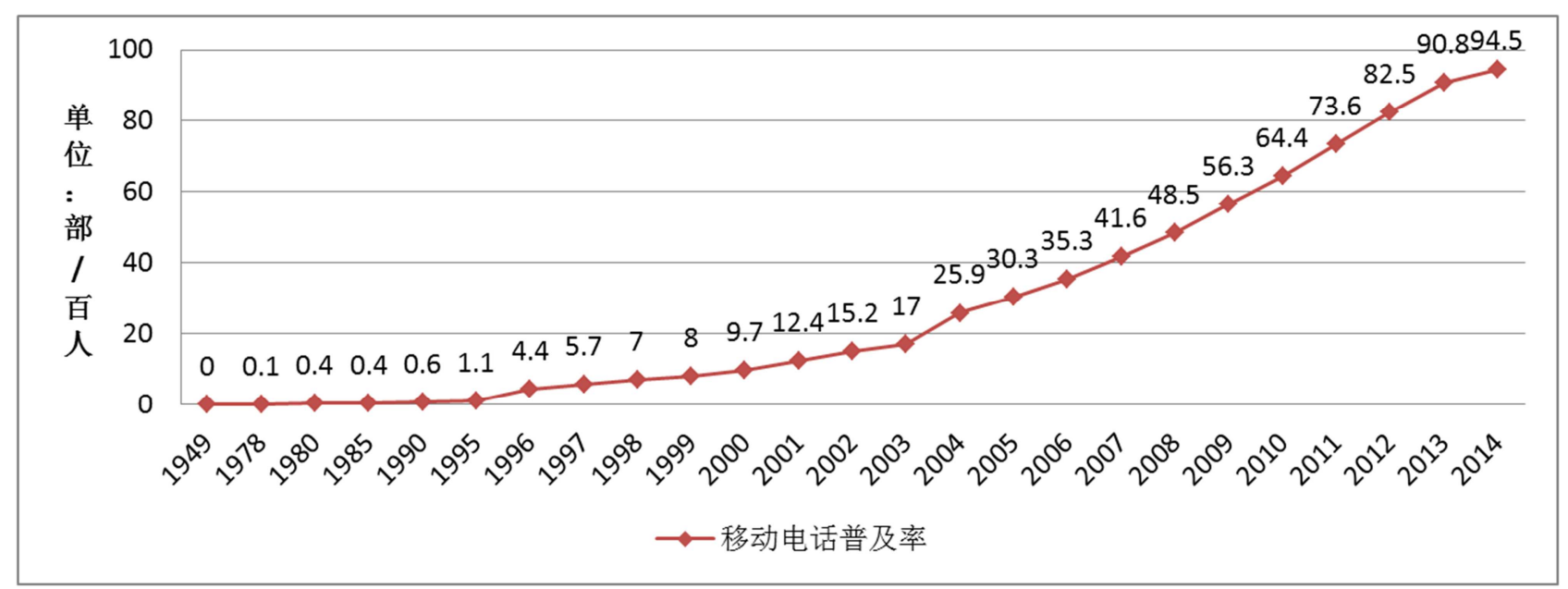

(数据来源：2014年通信运营业统计公报)

图7 1949-2014年移动电话普及率。 


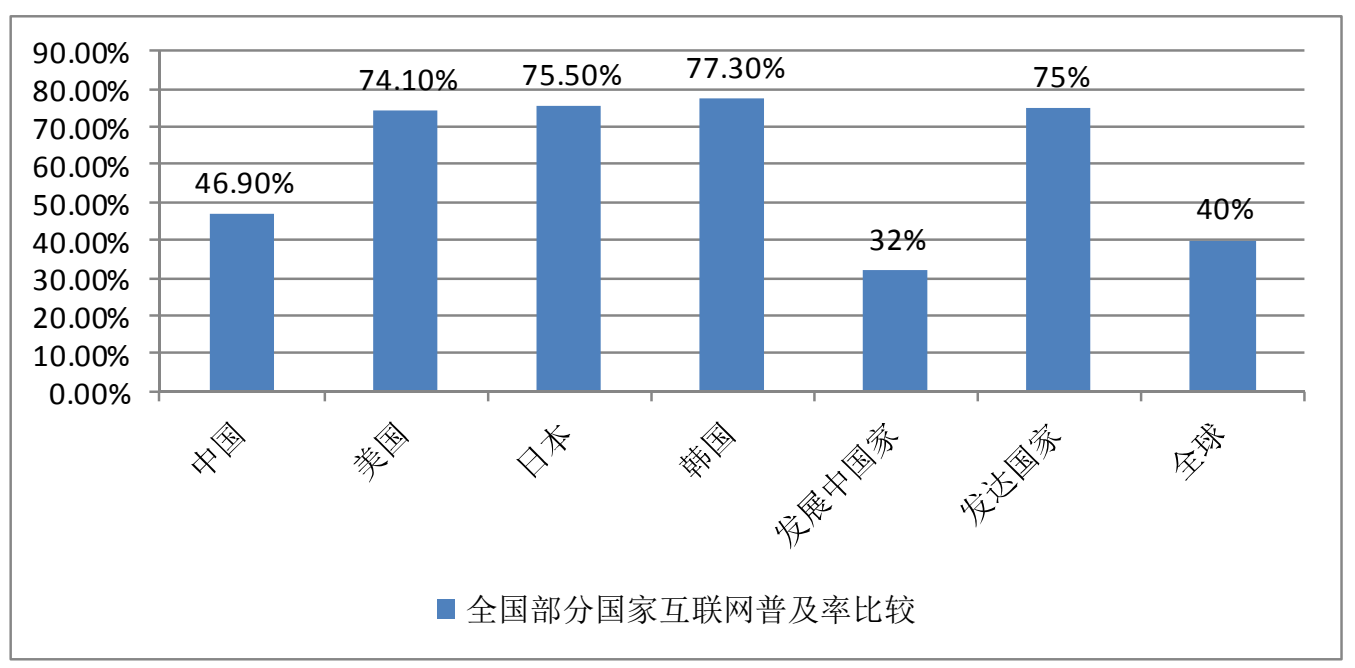

(数据来源: 国际电信联盟)

图8 2014年全国部分国家互联网普及率。

\section{3. 2. 传媒出版业对网络游戏产业竞争力的影响分析}

传媒出版业和网络游戏行业相互渗透, 相互影响。网 游这一新兴产业的发展极大地推动了媒体出版等行业的 发展, 为他们提供了一个新的商业平台, 而另一方面, 媒 体出版业为网络游戏行业提供了一个宣传渠道。

网络直播平台的出现是珄动网络游戏行业的电子竞 技市场变革的重要支点, 通过网络直播平台, 电子竞技的 受众迅速扩大, 并且形成了带有强标签色彩的用户群体。
作为新兴的流量平台, 游戏直播成为了链接厂商、媒体、 用户等各个环节的重要通道。自2013年起, 中国网络游戏 行业中开始出现大量的游戏直播平台, 比如YY游戏直播、 斗鱼TV、17173直播、PLU、战旗TV、风云直播等。各家纷 纷加入直播平台的混战, 从几千万到亚马逊收购视频游戏 直播平台Twitch, 花费9.7亿美元, 这都说明媒体行业和 网络游戏行业有着密切的战略合作关系。

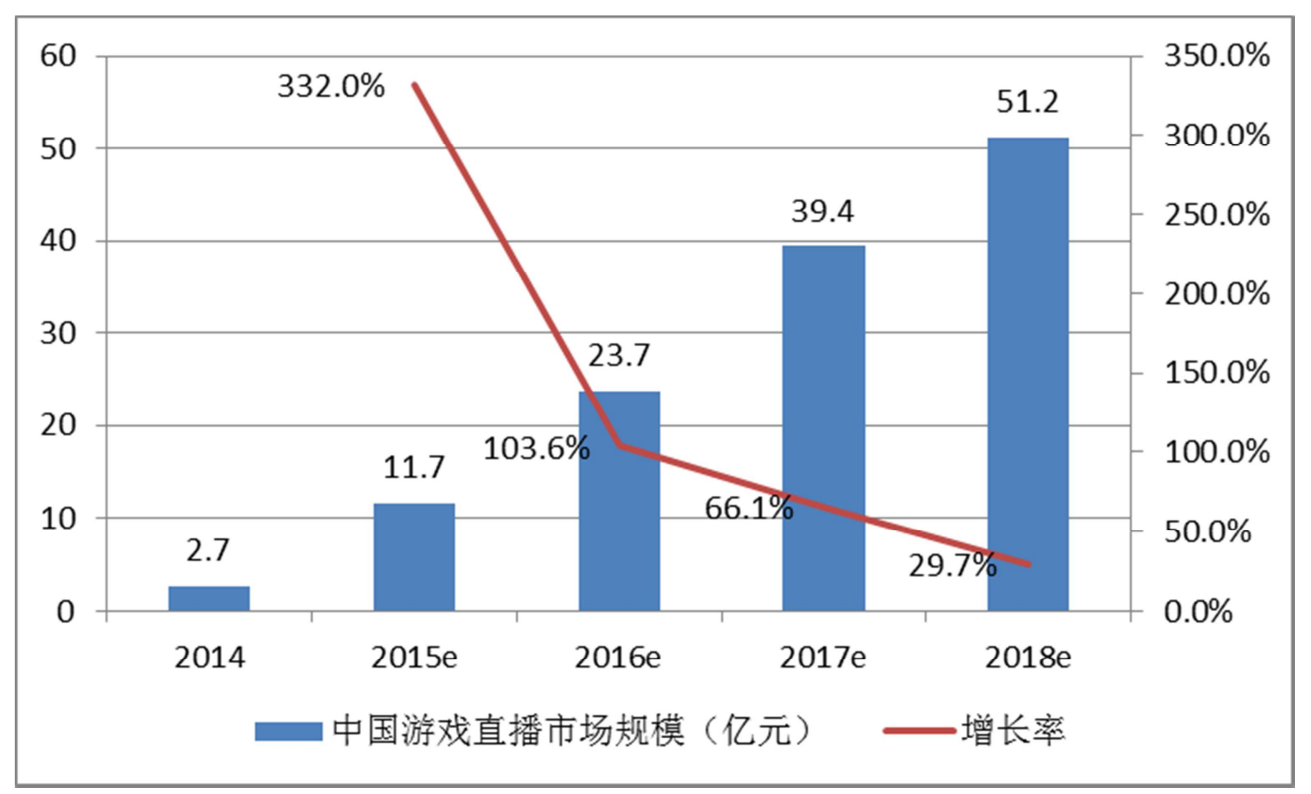

图9 2014-2018年中国游戏直播市场规模。

(注释: 中国游戏直播市场规模包括游戏直播平台及游戏内直播带来的增值服务、游戏联运、广告、会员等业务的收入) （数据来源：艾瑞咨询）

上图显示，2014年中国游戏直播市场规模已经达到 2.7 亿元，艾瑞咨询预计未来四年将有爆发性增长，因此 网络游戏产业和媒体产业之间的多元化经营模式也渐成 趋势, 这将促进网络游戏产业的进一步发展。

\section{3. 3. 融资体系对网络游戏产业竞争力的影响分析}

投融资体系主要包括投资管理、融资管理、过程控制 以及风险管理, 合起来就是资本运作。投融资体系是否完 
善直接影响到了一个国家产业竞争力的强弱。游戏企业选 择自主研发还是精品代理, 都必须具备游戏品质、网络社 区经营、网络管理技术、营销渠道四大要素。随着网络游 戏产品开发的可玩度以及精品度的增加, 开发周期也会越 来越长, 因此对于资金和人力的需求增大。目前, 国内民 间资本作为与游戏产业主要投资力量, 众筹作为辅助投资 力量, 两者正在改变游戏产业的投资环境。现在已有多家 游戏公司通过上市、融资、并购、收购等模式成功获得国 内外资本的支持。根据荷兰市场研究公司Newzoo发布了一 份全球游戏市场报告显示, 2014年腾讯是全球收入最高的 上市游戏公司, 72 亿美元的年收入比 2013 年增长了 $37 \%$; 而刚进军手游的阿里巴巴则于 2014 年在纽交所挂牌交易, 价格确定为每股 68 美元, 其股票当天开盘价为 92.7 美元, 阿里在交易中总共筹集到了 250 亿美元资金，创下了有史 以来规模最大的一桩IP0交易。这说明国内网游产业强劲 的增长动头吸引了众多创业资本的青崃, 高额的回报率也
激发了更多投资者的热情参与, 资本与游戏结合已经进入 了新的阶段。

\section{4. 企业战略、结构与竞争分析}

2014年, 上市游戏企业规模收入排名中, 腾讯依然居 于榜首, 网易和畅游紧随其后。2009年之前曾经在游戏业 界占据龙头地位的盛大游戏已经滑落到行业第五, 奇虎 360 凭借着网页端和移动端游戏的兴起居于行业第六, 37wan抓住了几年前网页游戏火爆的商机居于行业第七, 而老牌的经营客户端类游戏企业巨人网络和金山各自滑 落到第八位和第十一位, 紧接其后面的昆仑万维、百度、 中手游和乐逗把握了移动游戏的热销的时机也在游戏行 业占据了后几位。由图10可以看出, 腾讯的营业额是第二 位的四倍还要多, 居于游戏行业的霸主地位, 而盛大、完 美和畅游也仅仅只有行业第二网易的一半。这说明资源越 来越由少数几家占有, 市场朝着寡头垄断型市场趋势发展。

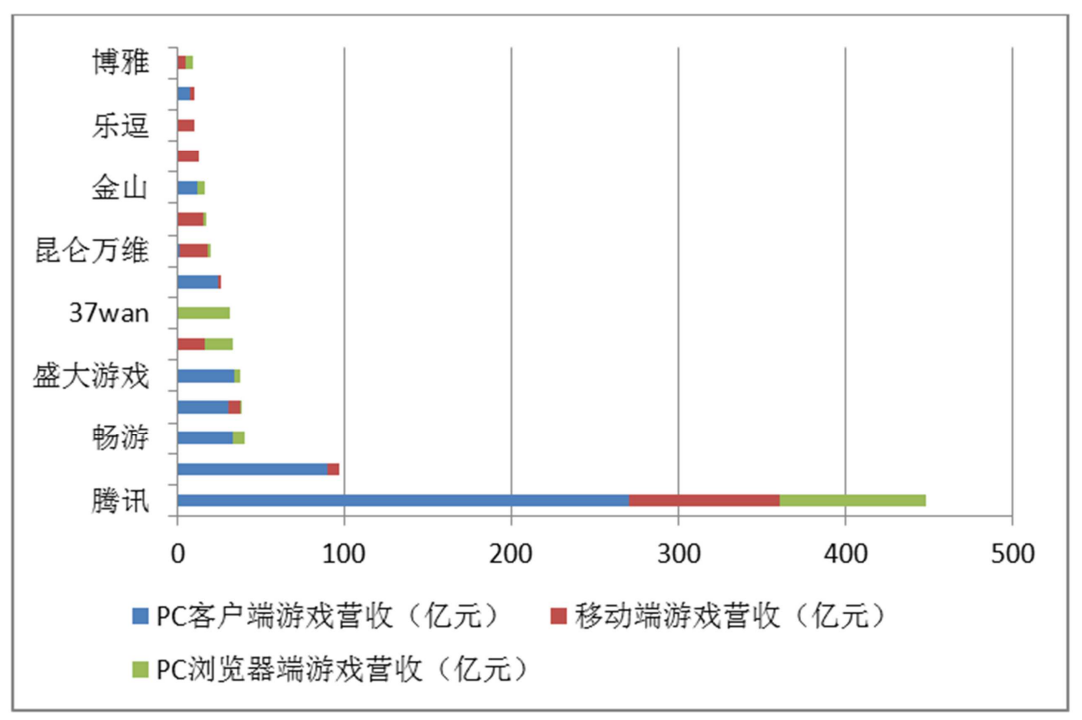

（数据来源：艾瑞咨询）

图10 2014年中国网络游戏上市规模TOP15。

企业战略和市场结构对于网络游戏行业发展具有颈 瓶作用。面对国内外行业的竞争压力, 企业只有自救才能 走出去, 在当前激烈的环境中生存下去。中国网络游戏行 业市场正往寡头型市场趋势发展, 资源将被少数几家大型 游戏企业占有, 提高了进入壁垒, 不利于中国网络游戏健 康发展, 这对于中小企业来说具有极大的挑战, 对此政府 应积极采取有利措施, 保护好中小企业利益, 为网络游戏 的长远发展提供优良的政策环境。

\section{5. 政府的作用分析}

政府对网络游戏行业发展中具有重要的支持地位,一 方面, 政府需要对网络游戏行业进行有效的监管, 特别是 在防治未成年人网瘾的过程中, 要严格实施, 杜绝未成年 人进网吧现象。另一方面政府需要向企业提供良好的发展 环境, 更要鼓励企业加快自主研发步伐, 提供政策支持。 目前, 中国在产业上依旧存在着产权保护、虚拟交易等问 题缺乏明确的法律约束。 [6]
2003年11月18日，电子竞技成为中国体育总局承认的 第99个正式体育项目, 这标志着中国电子竞技行业将进入 一个全新的阶段。整个游戏产业迈出了社会普遍认可的重 要一步。2014年, 中国电子竞技产业迎来了第二春一一WCA。 WCA创立于 2014 年, 是一项全球性的电子游戏竞技赛事, 该项赛事将继承和发扬WCG 世界电竞大赛的竞技体育精 神, 并由银川市政府、银川圣地国际游戏投资有限公司运 营, 这都将大大促进中国网络游戏行业的发展。

2014年，国务院在常务会议上确立了推进文化创意和 设计服务与相关产业融合发展的政策，提出要提升国家软 实力和产业竞争力, 推动文化产品和服务的生产、传播消 费的数字化、网络化进程; 习近平总书记在中央网络安全 和信息化领导小组第一次会议指出要把中国从网络大国 建设为网络强国, 强调要运用网络传播规律, 弘扬主规律, 激发正能量; 对于网络游戏产业而言, 作为网络强国战略 的重要组成部分, 同样担负起传播中国文化的历史和责任, 因此游戏产业要走可持续发展道路, 健康之路。 


\section{6. 知识吸收和创新的作用分析}

\section{6. 1. IP成为游戏市场产品要素分析}

IP指的是Intellectual Property, 即知识产权。知 识产权是一种无形的财产权, 也称智力成果权, 它指的是 通过智力创造性劳动所获得的成果, 并且是由智力劳动者 对成果依法享有的专有权利。2014年被网络游戏行业成为 IP元年, IP红利成为用户增长重要来源、以更低的成本获 得用户的重要手段, 成为游戏产品成功的 “催化剂”。IP 在手, 天下我有, 用渴求来形容行业对IP的需求并不恰当, 用饥渴也许更为合适。各大游戏厂商也纷纷从IP产品中受 益, 同时也是破解各类游戏同质化的突围的关键。在产品 投向市场的初期，原作积累的用户能迅速地转化为游戏的 玩家, 原作的IP价值也为产品的后续推广提供重要助力。 比如, 《梦幻西游》手游可以说是游戏自有IP的一个典型 代表。对于积累了数十年之久的客户端的用户玩家, 《梦 幻西游》手游不仅赚足了人气, 也吸引了无数新玩家的到 来, 给网易游戏添足了光彩。

\subsection{2. 创新对网络游戏产业竞争力的影响分析}

信息基础设施及硬件更新换代是创新的一个重要标 志。4G移动网络牌照的颁发和相关技术的普及为标志, iPhone 和Android 为代表的智能手机是改变移动互联网 的核心载体, 推动了中国互联网与网络游戏产业深度融合。 智能手机有着便于携带、在线时间长、能够随时随地为用 户服务的特点, 极大地扩展了 PC 互联网的时空范围。从 功能上讲, 智能手机大屏幕、高性能、易操作的特点为用 户提供了不亚于桌面PC 的使用体验, 从而能够使传统的 互联网业务自然地迁移到移动领域。此外, 智能手机还具 备通话、位置定位、多媒体信息采集等特点, 能够为用户 提供不同于PC 互联网的服务。

在众多的移动服务中, 移动游戏很好地结合了移动终 端便携性特点与现代人的碎片化的娱乐需求, 衍生出很多 有异于PC 端游戏的新特性。而智能移动终端设备升级换 代, 迎来新一轮价格下调, 不仅为网络游戏用户提供了更 宽松的体验环境, 也为开发更多的人机交互、社交场景等 娱乐模式提供了硬件条件, 这让移动游戏在众多移动应用 中脱颖而出。

网络游戏产业属于网络游戏创意行业, 只有具备创意 的玩法的游戏产品才能吸引人们眼球, 游戏世界规则趋向 框架化, 面对用户体验简单自由, 让用户群切切实实的体 验到游戏带来的乐趣, 才能抓住用户以维护用户。

\section{7. 机遇分析}

在波特的钻石模型中，除了四个基本要素外，还有 两个变量一机会和政府。机会是可遇不可求的, 对一个 产业的竞争力而言, 机会可能与该国的环境无关, 甚至 同企业内部也没有关系，政府也难以施加影响。一般情 况下, 可能形成机会的情形有如下几种: 基础科技的发 明创新、传统技术出现断层、生产成本突然提高、全球 金融市场或汇率的重大变化、全球或区域市场的需求剧 增、外国政府的重大决策、爆发战争等。这些情况下，
可能对一个国家的产业意味着难得的机会。而企业只能 改变原有的发展路径, 采用新的方式才能获得发展, 或 者占有更高的市场份额。

2001年初, 在网络泡沫之后, 陈天桥用仅存的 30 万 美元孤注一掷, 与韩国Actoz公司签约获得《传奇》游戏 的运营权; 而在游戏正式运营仅 4 个月后, 《传奇》便成 了世界第一大 (平均在线数最多) 网络游戏; 2004年, 盛大在全球拥有 3 亿注册用户, 平均每天同时在线人数 230 万。那年 5 月 13 日, 盛大网络在纳斯达克上市。在 8 月 10 日首次公布财报之后, 盛大股价一路攀升至 21.22 美元。此时盛大市值已达 14.8 亿美元, 成为纳斯达克市 值最高的中国概念网络股。陈天桥也因此成为了当时的 中国首富, 仅仅靠一家经营网络游戏的网站就创造了一 个财富神话。

\section{4. 中国网络游戏产业竞争力的提升对策}

\section{1. 网络游戏产业人力资源建设策略}

创意产业发展, 核心资源在于人才, 然而中国的网络 游戏产业相关人才一直存在很大的缺口, 这种情况的出现 与中国日益扩大的网络游戏市场规模相矛盾着, 这极大的 制约了中国网络游戏行业的发展。目前, 虽然在国内举办 了一些类似于ChinaJoy这样的大型网络游戏展览, 但这远 远不够, 应努力打造行业间的具有国际水平的交流平台, 通过高水平的交流和沟通, 激发行业人士的创意与激情, 从而为更好的发展网络游戏打造人才基础。

人才的培养同样也需要政府、企业与学校三方共同合 作来完成。政府应鼓励各高校建立网络游戏人才培养系统, 与各大游戏企业对接的人才培育基地, 鼓励企业加大对员 工的出国深造，增强国际间的学习和交流，从而为中国的 网络游戏行业注入更多新鲜血液, 促进中国游戏产业茁壮 成长。[7]

\section{2. 网络游戏产业资本投入策略}

相比于世界其他网络游戏产业发展较好的国家, 中国 网络游戏产业投入运营时间较短, 体制尚不健全, 从而出 现各种各样的问题, 因此网络游戏产业资本投入保障体系 的构建势在必行, 同时需要设置网络游戏产业专业融资担 保机构。商业银行可以根据企业的申请条件和资质评估, 发放贷款。政府应为各大企业尤其是研发企业搭设各种融 资渠道。吸引民间闲散资金注入网络游戏业务, 为网络游 戏行业发展注入活力。

\section{3. 网络游戏产业企业战略}

网络游戏产品是给消费者带来的精神层面的体验和 感受，给消费者缓解现实生活中的压力，其核心在于是否 满足消费者的精神需求。各大企业应该积极战略布局, 从 消费者的角度出发, 自主研发出适合各阶层次, 各年龄阶 段的游戏产品。面对美日韩等网络游戏强国, 应积极取精, 将带有中国元素的加入到新的游戏中, 而不是一味的寻求 和国外游戏公司代理，模仿他们的游戏作品。[9] 


\section{4. 政府政策}

首先，政府应加大扶持游戏产业政策，如对重点游戏 企业实行各种税制优惠政策等。提高行政监管效率，有效 保护知识产权, 打击盗版。由于目前游戏行业呈现出 “效 率市场”特征, 产品研发周期压缩、数量呈现爆发性增长, 这为游戏出版加大了难度。而专门针对移动游戏的管理方 案还未出台, 尚无新规对游戏出版进行调整和规范, 这使 得一些企业打政策擦边球，在后期监管和运营出现漏洞， 给整个游戏行业带来隐患。因此政府应早日完善游戏产业 的相关法律法规，给游戏行业创造良好的政策坏境。[8]

其次, 政府要完善未成年人网络游戏防沉迷体制, 为 未成年的身心健康提供良好的法律保障。

最后，“私服” “外挂” 必须严厉打击。开发游戏、 代理游戏以及其他任何的游戏经营都需要付出相当大的 成本。然而 “私服” “外挂” 的出现, 其严重侵犯知识产 权不止, 更重要的是严重扰乱市场秩序, 极大的影响到了 游戏企业的正常运营收益。因此, 游戏开发商和代理商的 正当权益想要得到保护要保护, 就必须要严厉打击 “私服” “外挂”; 此外, 国家的相关职能部门之间应相互配合, 共同制裁 “私服” “外挂” ; 同时, 游戏企业自身也要加 强技术公关及技术防护，增强自身对 “私服” “外挂” 的发现和封堵能力。

\section{5 . 网络游戏创新策略}

网络游戏创新分为内容上的创新和技术上的创新。由 于中国网络游戏的主要的商业模式是和国外游戏公司合 作代理, 导致本土游戏一味的追求模仿外国作品而无法满 足游戏玩家的需求。

因此首先是要做好内容创新。目前中国的自主创新产 品的内容大致围绕着中国历史这个角度出发, 如剑网三, 大话西游等。虽然中国的上下五千年历史以及神话故事给 了中国本土网络游戏取材提供了较大的空间, 但是也给本 国研发人员的创意思维带来了一定的局限性。这种局限性 带来的游戏作品会使得一部分对历史文化不感兴趣的玩 家造成流失。并且, 当大部分玩家发现这些游戏都是同类 产品的时候, 会产生一种厌倦的心理状态, 这非常不利于 中国网络游戏的发展。所以, 当今企业应该鼓励研发人员 跳出历史的圈子, 积极从生活中发现素材, 电影、动漫等 素材都是不错的闪光点。

其次要做到技术创新。当有了一个好的构思、创意之 后, 如果技术跟不上, 那么一切都是空谈。对于玩家来说, 除了游戏的可玩性以外, 游戏画面的精致程度、游戏的背 景音乐、 $3 \mathrm{D}$ 的体验感、游戏的打击感都是衡量一个游戏 是否值得一玩的试金石。而对于一个游戏制作过程中，除 了需要经验丰富的研发人员外, 另一个重要的是具有自主 知识产权的网络游戏通用引擎。它代表着一个网络游戏企 业参与国际竞争的核心竞争力。目前, 中国游戏市场上, 自主研发的引擎相比国外成熟的引擎还是有很大的差距, 这主要体验在游戏的流畅度和精美度上。再加上中国大部 分企业的目的是为了盈利, 而不是为了开发出精美的游戏 为目的, 这在客观上也导致了中国研发游戏时间短, 资金 有限, 一部分具有创意的作品也因此只做出了半成品, 严
重影响了玩家游戏体验。[10]因此加强技术层面的创新具 有重大的战略和现实意义。

\section{5. 结论}

回顾中国网络游戏产业近年来的发展历程, 网络游戏 已成为发展最迅速的文化创意产业之一, 有着令人瞩目的 市场规模和前景。本文从产业经济学的角度, 结合波特的 钻石模型, 客观定性地分析、比较和评价中国网络游戏产 业竞争力的状况, 得出以下结论:

1. 中国网络游戏产业规模扩张迅速, 手机游戏成为中 国网络游戏产业的新的增长点, 中国网络游戏产业竞争力 水平逐步增强。互联网行业、计算机行业、手机、移动 $4 \mathrm{G}$ 行业的快速发展促进产生了巨大的网络游戏用户群, 同样 也刺激了中国网络游戏产业的迅猛发展。

2. 中国网络游戏产业相对于韩国自主研发能力明显 不足, 游戏同质化现象严重, 应加大人力资源建设, 整合 技术平台, 以产业集群打造整体优势, 行业融合优化产业 结构等方式提升产业的竞争力。

3. 中国网络游戏创新力度不足。在内容上容易受到中 国历史文化的限制, 在技术上表现在很少有自主知识产权 的网络游戏通用引擎。网络游戏企业应加大研发创新力度, 更新盈利模式, 做出高品质的游戏作品。

\section{参考文献}

１１］上海艾瑞市场咨询有限公司.《中国网络游戏行业年度监测 报告简版2015年》[R].2015。

[2] 迈克尔・波特著, 李明轩, 邱如美译. 国家竞争优势. 北京: 中 信出版社, 2012 。

[3] 茵明杰. 产业竞争力的 “新钻石模型” $[\mathrm{A}]$, , 社会科 学, 2006 (04) :68-73。

[4] 高嘉阳. 基于钻石模型的中韩网络游戏产业竞争因素对比 分析 [A]. 产能经济, 2015(05):39。

[5] 中国互联网信息中心 (CNNIC)。《第31次中国互联网络发展 状况统计报告》[R].2013。

[6] 王寅. 中国网络游戏市场法律监管的必要性 [B]. 山西高等 学校社会科学学报, 2010(06): 54-57。

[7] 刘文, 张丹. 中韩游戏产业发展比较研究 [A]. 贵州社会科 学, 2015 (04): 112-119。

[8] 刘胜枝, 张小凡. 网络游戏产业发展中政府管理的路径分析 [A]. 编辑之友, 2015（05）：24-27。

[9] 周笑冰. 韩国政府的游戏产业扶持政策及启示特区 $[\mathrm{J}]$. 实 践与理论, 2012 (06): 60-63。

[10］欧阳桃花, 武光, 于金. 社交网络游戏企业的快经营商业模 式研究一一基于企业伦理视角 [A]. 管理案例研究与评论, 2014（06）:449-463。 